\title{
OS ESTUDOS DE GÊNERO EM REVISTAS CIENTÍFICAS DO FEPAE-NN: uma revisão sistematizada
}

\author{
Alfrancio Ferreira Dias ${ }^{1}$ \\ Ivanderson Pereira da Silva² \\ Pedro Paulo Souza Rios ${ }^{3}$
}

\begin{abstract}
RESUMO
Esse estudo investigou os avanços na produção do conhecimento sobre gênero nos periódicos da área de educação, filiados ao Fórum de Editores de Periódicos da Área de Educação - FEPAE/ANPED-Norte/Nordeste. Para isso, foi realizada uma revisão sistematizada da literatura dos estudos que foram publicados nessas revistas no período de 2014 a 2019 e que tinham como foco as questões de gênero. Concluiu-se, que esse campo de estudos está engajado com questões político-pedagógicas ligadas ao desmonte da sociedade cisheteronormativa, com vistas à construção de uma sociedade igualitária e tem contribuindo para a desestabilização de normatizações, classificações e hierarquizações no campo da educação.
\end{abstract}

Palavras-chave: Gênero. Educação. Revisão sistematizada.

\section{THE GENDER STUDIES IN FEPAE-NN SCIENTIFIC JOURNALS: a systematic review}

\begin{abstract}
This study investigated advances in the production of knowledge about gender in education journals, affiliated to the Forum of Editors of Education Journals - FEPAE/ANPEDNorte/Nordeste. For this, a systematic review of the literature of the studies that were published in these journals from 2014 to 2019 and that focused on gender issues was carried out. It was concluded that this field of studies is engaged with political-pedagogical issues related to the dismantling of cisheteronormative society, with a view to building an egalitarian society and has contributed to the destabilization of norms, classifications and hierarchies in the field of education.
\end{abstract}

Keywords: Gender. Education. Systematic review.

ESTUDIOS DE GÉNERO EN REVISTAS CIENTÍFICAS FEPAE-NN: una revisión sistemática

\section{RESUMEN}

1 Doutor em Sociologia. Bolsista de Produtividade em Pesquisa (PQ2) do CNPq. Professor Permanente do Programa de Pós-graduação em Educação da Universidade Federal de Sergipe. ORCID ID: https://orcid.org/0000-0002-5562-0085 E-mail: diasalfrancio@gmail.com 2 Doutor em Educação. Bolsista do Programa de Pós-Doutorado (PNPD/ CAPES) junto ao Programa de Pós-graduação em Educação da Universidade Federal de Sergipe. Professor do Programa de Pós-graduação em Ensino de Ciências e Matemática da Universidade Federal de Alagoas. ORCID ID: https://orcid.org/0000-0001-9565-8785 E-mail: ivanderson@gmail.com

${ }^{3}$ Doutor em Educação. Realiza estágio de pós-doutoramento junto ao Programa de Pósgraduação em Educação da Universidade Federal de Sergipe. Professor da Universidade do Estado da Bahia, Departamento de Educação, Curso de Graduação em Pedagogia. ORCID ID: https://orcid.org/0000-0001-7981-9091 E-mail: peudesouza@yahoo.com.br 
Este estudio investigó los avances en la producción de conocimiento sobre género en revistas de educación, afiliadas al Foro de Editores de Revistas de Educación - FEPAE / ANPED-Norte / Nordeste. Para ello, se realizó una revisión sistemática de la literatura de los estudios que se publicaron en estas revistas de 2014 a 2019 y que se centró en cuestiones de género. Se concluyó que este campo de estudios se dedica a cuestiones políticopedagógicas relacionadas con el desmantelamiento de la sociedad cisheteronormativa, con miras a construir una sociedad igualitaria y ha contribuido a la desestabilización de las normas, clasificaciones y jerarquías en el campo de la educación.

Palabras clave: Género Educación. Revisión sistemática.

\section{INTRODUÇÃO}

Os estudos sobre as relações entre Gênero e Educação, embora tenham avançado no Brasil a partir do final do século XX (SILVA, MAGALHÃES, SILVA, 2019), no contexto atual, vêm sendo duramente atacada por um conjunto de políticas e ações governamentais que visam silenciar e/ou polarizar esse debate ${ }^{4}$. Contudo, têm-se avançado nesse campo de estudos e faz necessário apontar tais avanços. Nesse sentido, a produção do conhecimento sobre gênero e suas interfaces com pesquisas que tomam como foco questões relacionadas ao corpo e às sexualidades tem sido objeto de estudos de revisão.

O trabalho de Dias e Amorim (2015) sistematizou a literatura específica sobre corpo, gênero, sexualidades e educação, usando a base de dados SCIELO. Os autores verificaram que, um elemento comum entre os estudos analisados é "o fato de que todos (com maior ou menor grau de intensidade) sugerem que a abordagem das temáticas contribui para a desestabilização de normatizações, classificações e hierarquizações no


e Rios (2020) analisou a produção do conhecimento específica sobre gênero

\footnotetext{
${ }_{4}^{4}$ No Brasil, o ano de 2013 foi marcado pelas jornadas de protestos contra o aumento da passagem de ônibus. Em janeiro do mesmo ano, na França, os protestos já antecipavam um movimento latente no Brasil e eclodiria no ano de 2014 no âmbito das discussões em torno do Plano Nacional de Educação e consequentemente dos Planos Estaduais e Municipais de Educação. O mote dos protestos era o ataque católico contra o que se vinha conformando como a luta contra a Ideologia de Gênero (SILVA, 2018).

5 Sobre isso ver Coorper (2010) e Figueiredo Filho et al. (2014). Os autores sugerem que o planejamento de pesquisa está organizado em sete etapas: a) identificação e formulação do problema de pesquisa; b) coleção de literatura; c) coleta de informações de cada estudo; d) avaliação da qualidade dos estudos; e) análise e síntese dos resultados dos estudos; f) interpretação dos dados coletados; e g) apresentação dos resultados.
} 
publicada em um periódico específico da área de educação, editado por uma instituição do Nordeste brasileiro. Os resultados dessa investigação sugerem uma "significativa ampliação na produção científica dos estudos de gênero, contribuindo para a desestabilização de normatizações, classificações e hierarquizações no campo da educação" (SILVA; DIAS; RIOS, 2020, p. 150).

Em ambos estudos, a revisão sistemática de literatura, enquanto abordagem metodológica, favoreceu um "aumento da acumulação e a confiabilidade da produção do conhecimento científico" (DIAS; AMORIM, 2015, p. 194). Em face desse potencial, investimos na continuidade da investigação empreendida por Silva, Dias e Rios (2020). Nesse sentido, tivemos por objetivo central investigar os avanços na produção do conhecimento sobre gênero nos periódicos da área de educação, filiados ao Fórum de Editores de Periódicos da Área de Educação - FEPAE/ANPEDNorte/Nordeste. A questão norteadora do estudo foi: o que os estudos publicados nesses periódicos evidenciam?

\section{O PROCESSO DA REVISÃO SISTEMATIZADA}

A abordagem de revisão sistematizada vem sendo introduzida nas pesquisas de Ciências Humanas na última década, seguindo a dinâmica da produção científica global (SANTOS; SILVA, 2019; SILVA; MERCADO, 2019; 2018; 2015; SILVA; SILVA, 2017; NUNES; SILVA; MERCADO, 2016).

Segundo Silva, Dias e Rios (2020), essa abordagem consiste em apontar o que já se produziu a respeito de um determinado tema, bem como em contribuir para a "[...] a concentração de resultados de vários outros estudos num mesmo trabalho" (DIAS; AMORIM, 2015, p. 196). Nesse sentido, para o desenvolvimento da revisão sistematizada, optamos pelos seguintes critérios de inclusão e exclusão: a) os periódicos deveriam estar filiados ao FEPAE-NN; b) esses deveriam estar indexados na Web of Science; c) os estudos deveriam ter sido publicados no período de 2014 a 2019; d) não foram traçados cortes de restrição de artigos quanto ao idioma; c) o termo 
"gênero" deveria estar presente no título, no resumo ou nas palavras-chave do artigo.

Foi realizada uma análise inicial nos periódicos filiados ao FEPAE-NN e apenas três periódicos estão indexados na base Web of Science: Revista Tempos e Espaços em Educação (ISSN: 2358-1425), Revista Educação \& Formação (ISSN: 2448-3583) e a Revista Práxis Educacional (ISSN: 2178-2679), todas vinculadas a instituições públicas na região Nordeste. Para ampliar a abrangência do estudo e contemplar ao menos um periódico da região Norte do país, incluímos a Revista Exitus (ISSN 2237-9460), editada pela Universidade Federal do Oeste do Pará (UFOPA). A inclusão desse periódico se justifica por ser essa a única revista editada por uma instituição da região Norte que está indexada na base Educ@ da Fundação Carlos Chargas.

Nesse sentido, foram levantados e analisados estudos sobre gênero, publicados nesses quatro periódicos, no período de 2014-2019.

\section{RESULTADOS E DISCUSSÕES}

A seleção de estudos nesses quatro periódicos à luz dos critérios de inclusão/exclusão supracitados nos permitiu trazer à baila: 40 artigos da Revista Tempos e Espaços em Educação; 06 da Revista Exitus, 05 da Revista Educação \& Formação e 09 da Revista Práxis Educacional. Esse primeiro movimento evidenciou um total de 60 trabalhos, publicados no período de 2014-2019 com foco em fenômenos emergentes das relações entre gênero e educação. Observa-se que $66,67 \%$ dos estudos que compõem esse levantamento foram publicados pela Revista Tempos e Espaços em Educação; 15\% foram divulgados pela Revista Práxis Educacional, 10\% pela Revista Exitus; e 8,34\% pela Revista Educação \& Formação.

Ao verificar o índice de citação desses periódicos no Google Acadêmico, identificamos que a Revista Práxis Educacional possuía índice h = 14 e i10 = 24; a Revista Tempos e Espaços em Educação, $h=11$ e i10 = 14; a Revista Exitus, $h=8$ e $i 10$ = 7; e a Revista Educação \& Formação, $h=4$ e $i 10=$ 0. 
Sobre índice de citação na Web of Science, a Revista Tempos e Espaços em Educação possui um índice $h=3$, a Revista Educação \& Formação $h=1$ e a Revista Práxis Educacional $h=1$. A Revista Exitus, até o momento desse estudo não estava indexada na Web of Science.

Com relação às abordagens metodológicas utilizadas nos estudos levantados, é possível observar sua distribuição de frequência a partir do quadro 1.

QUADRO 1 - Abordagens metodológicas utilizadas nos estudos levantados

\begin{tabular}{|c|c|c|c|}
\hline Abordagem & Qt & $\%$ & Estudo \\
\hline Análise fílmica & 4 & 6,66 & $\begin{array}{l}\text { Anjos e Cardoso (2014); Guzzi (2019); Darsie et al. (2018); } \\
\text { Abib (2018) }\end{array}$ \\
\hline $\begin{array}{l}\text { Análise de } \\
\text { imagens }\end{array}$ & 1 & 1,66 & Almeida (2017) \\
\hline $\begin{array}{l}\text { Análise de } \\
\text { narrativas }\end{array}$ & 6 & 10 & $\begin{array}{l}\text { França e Ferrari (2016); Morais e Carvalho (2015); Santana } \\
\text { (2014); Santos e Feldens (2019); Gordo, Bentes e Alameira } \\
\text { (2018); Rios, Cardoso e Dias (2018) }\end{array}$ \\
\hline $\begin{array}{l}\text { (Auto)Biografia, } \\
\text { história de vida }\end{array}$ & 11 & 18,33 & $\begin{array}{l}\text { Carvalho et al. (2017); Sarat e Campos (2014); Silva (2014); } \\
\text { Rios, Dias e Brazão (2019); Silva e Pinheiro (2019); Oliveira e } \\
\text { Martiniak (2018); Soares e Viana (2016); Montenegro } \\
\text { (2019); Miranda (2018); Araújo, Cunha e Alcântara (2018); } \\
\text { Blanchard e Muzás (2015) }\end{array}$ \\
\hline $\begin{array}{l}\text { Ensaios/Pesquisa } \\
\text { bibliográfica }\end{array}$ & 15 & 25 & $\begin{array}{l}\text { Bogossian (2014); Canotilho, Araujo e Oliveira (2014); } \\
\text { Cardoso (2019); Cruz (2014); Dias (2014); Dias et al. (2017); } \\
\text { Donato e Tonelli (2019); Dubet (2018); Ferreira (2014); } \\
\text { Kaplan e Xavier (2018); Preinfalk-Fernández (2016); } \\
\text { Santana et al. (2016); Thürler e Santos (2014); Vieira e } \\
\text { Coelho (2014); Silva Junior (2016) }\end{array}$ \\
\hline $\begin{array}{l}\text { Estudos } \\
\text { comparados }\end{array}$ & 1 & 1,66 & Kaplan e Xavier (2018) \\
\hline $\begin{array}{l}\text { Pesquisa de } \\
\text { campo }\end{array}$ & 9 & 15 & $\begin{array}{l}\text { Araújo e Barros (2017); Couto e Cruz (2017); Di Gregorio e } \\
\text { Silva (2014); Rodrigues e Faro (2019); Silva e Tavares (2019); } \\
\text { Bastos e Eiterer (2017); Junior, Aguiar e Maia (2019); } \\
\text { Cardoso e Dias (2016); Oliveira (2014) }\end{array}$ \\
\hline $\begin{array}{l}\text { Pesquisa } \\
\text { documental }\end{array}$ & 7 & 11,66 & $\begin{array}{l}\text { Becker e Oliveira (2016); Costa e Macarro (2016); Galak } \\
\text { (2017); Rodrigues (2016); Santos e Lage (2017); Souza } \\
\text { (2014); Piava e Momma-Bardela (2016) }\end{array}$ \\
\hline Pesquisa-ação & 2 & 3,33 & Silva Junior e Ivenicki (2019); Martines e Rossarolla (2018) \\
\hline $\begin{array}{l}\text { Pesquisa } \\
\text { quantiqualitativa }\end{array}$ & 1 & 1,66 & Pinto, Carvalho e Rabay (2017) \\
\hline Pesquisa on-line & 1 & 1,66 & Porto e Galvão (2016) \\
\hline $\begin{array}{l}\text { Pesquisa } \\
\text { exploratória }\end{array}$ & 2 & 3,33 & Eugênio e Lima (2015); Schutz, Martinez e Salva (2019) \\
\hline
\end{tabular}

Fonte: Elaboração dos autores (2020) 
O quadro 1 foi constituído a partir da abordagem metodológica que foi anunciada pelos autores no corpo do texto. Observa-se que os estudos dos tipos "Ensaios/Pesquisa bibliográfica" ou "(Auto)Biografia, história de vida" compõem cerca de $45 \%$ de toda produção científica do campo do gênero divulgada, no período de 2014 a 2019, nessas revistas. Em contraposição, evidencia-se uma baixa recorrência de estudos comparados, pesquisas-ação, pesquisas exploratórias, estudos quantiqualitativos, análises de imagens e pesquisas on-line. Esse quadro sinaliza para a necessidade do desenvolvimento de estudos que investiguem os fenômenos emergentes das relações entre gênero e educação a partir dessas abordagens metodológicas com vistas ao aprofundamento desse campo de pesquisa.

A análise dos resultados dos 60 estudos favoreceu a emergência de sete seguintes categorias. A distribuição de estudos por categoria variou de $6,67 \%$ a 18,33\%. Isso sinaliza que essa distribuição não foi randômica. As categorias emergentes e a concentração de estudos nelas agrupados pode ser verificada a seguir: a) Gênero e sexualidade como condicionantes da profissionalização dos sujeitos (04 estudos / 6,67\%); b) Multiculturalismo e estudos interseccionais ( 11 estudos / 18,33\%); c) Norma de gênero e corpo (10 estudos /16,66\%); d) Contribuições de pensadores/correntes teóricas para os estudos de gênero (07 estudos / 11,66\%); e) Concepções acerca da mulher e seu papel social na contemporaneidade ( 11 estudos / 18,33\%); f) Gênero, sexualidade e currículo (10 estudos / 16,66\%); e g) Invisibilidade de gênero (07 estudos / 11,66\%).

$\mathrm{Na}$ categoria Gênero e sexualidade como condicionantes da profissionalização dos sujeitos ${ }^{6}$, os estudos de Dubet (2018, p. 9), Bastos e Eiterer (2017), Soares e Viana (2016), Araújo, Cunha e Alcântara (2018)

\footnotetext{
6 Sobre profissionalização e formação ver os trabalhos de Bego (2016), Lima e Santos (2018), Morocó (2017), Genú (2017), Junges, Ketzer e Oliveira (2018), Banfield, Haduntz e Maisuria (2016), Oliveira, Gerevini e Strohschoen (2017), Corradini e Mizukami (2017), Barolli e Villani (2016), Tancred e Reali (2017), Tancredi, (2017), Souza (2017), Oliveira e Guimarães (2014), Souza e Bonilla (2014), Lucena e Oliveira (2014).
} 
apontam as implicações gênero e da sexualidade nos encaminhamentos e percursos profissionais, implicando numa dicotomia e binaridade discursiva que privilegia nesse os homens, como melhores oportunidades de trabalho, acesso profissional, salários, e reconhecimento social. A heteronormatividade produz um discurso que naturaliza e condicionada pelas múltiplas variáveis que definem papéis sociais específicos para as mulheres e papéis sociais específicos para os homens. Assim, passamos a vivenciar e produzir e reproduzir concepções de gênero e sexualidade nas sociabilidades binárias, sendo exigidas ações que correspondam aos comportamentos "ditos" do masculino e do feminino. Isso gera implicações e desigualdades sociais, principalmente, por desconsiderar outras formas de viver e performatizar as experiências de gênero e sexualidades outras.

Com 18,33\% dos estudos incluídos, a categoria Multiculturalismo e estudos interseccionais, compartilha a preocupação com as implicações que as intersecções de gênero, raça, religião, geração ou classe social trazem para o desenvolvimento das pessoas. Os estudos evidenciam que esses marcadores sociais tencionam as identificações, individualidades e subjetividades das pessoas. Além disso, destacam que o multiculturalismo e a interseccionalidade contribuem para celebrar a diferença e subsidiar o trabalho pedagógico na escola com as temáticas de gênero, sexualidades e racismo (EUGÊNIO; LIMA, 2015; FERREIRA, 2014; KAPLAN; XAVIER, 2018; RODRIGUES; FARO, 2019; SILVA, 2014; SILVA JUNIOR; IVENICKI, 2019; SOUZA, 2014; SILVA; PINHEIRO, 2019; PAIVA; MOMMA-BARDELA, 2016; MONTENEGRO, et al., 2019; ABIB, et al., 2018).

Incluímos 10 estudos $(16,66 \%)$ no êxito Norma de gênero e corpo: Almeida (2017), Anjos e Cardoso (2014), Cardoso (2018), Dias (2014), Dias et al. (2017), Galak (2017), Guzzi (2019), Thürler e Santos (2014) Rios, Cardoso e Dias (2018) e Rios, Dias e Brazão (2019). Esses estudos problematizam as normalizações sociais que regulam os corpos, os gêneros e as sexualidades nas instituições de ensino, bem como as estratégias discursivas produzidas e reproduzidas para uma escolarização das experiências desviantes para estabelecida pela cisheteronormatividade, tais como brinquedos, 
brincadeiras, objetos, uniformes, lugares, cores, matérias, uso da linguagem etc. Ou seja, uma produção de uma escolarização generificada, que conduz a mecanismos de normalização, onde há a separação de indivíduos "normais" e "anormais". Por outro lado, a norma de gênero nesse processo também é subvertida na vivência cotidiana. Na medida em que a norma é concretizada, ela é também desconstruída por corpos desviantes que problematizam uma educação libertadora e como prática de liberdade.

Os estudos de Becker e Oliveira (2016), Cardoso (2019), Cruz (2014), Dias e Menezes (2018), Silva Junior e Ivenicki (2019), Silva Junior (2016) e Miranda (2018) foram incluídos na categoria Contribuições de pensadores/correntes teóricas para os estudos de gênero, correspondendo a $11,66 \%$ dos estudos incluídos. Nesses estudos são problematizadas as correntes teóricas que têm contribuído para o avanço dos estudos de gênero e sua interseccionalidade com outros marcadores da diferença, bem como a potencialidade dos estudos trans* e queer para proposições de novas pedagogias transformadoras.

Na categoria Concepções acerca da mulher e seu papel social na contemporaneidade foram incluídos 11 estudos (18,33\%): Araújo e Barros (2017), Canotilho, Araujo e Oliveira (2014), Carvalho et al. (2017), Morais e Carvalho (2015), Sarat e Campos (2014), Porto e Galvão (2016), Santos e Feldens (2019), Silva e Tavares (2019), Oliveira e Martiniak (2018), Darsie, et al. (2018) e Blanchard e Muzás (2015). Esses estudos tencionam a produção discursiva acerca da mulher e seu papel no campo da educação e para além dele, como as militâncias em movimento estudantis e sindicais, movimento de ocupações e outros espaços de discussão que priorizem as Iutas contra as injustiças e construção de uma sociedade mais igualitária, ou seja, como vivências mais democráticas e de ambientes propício à discussão dos direitos humanos.

Os estudos de Couto e Cruz (2017); Dias e Menezes (2018); Rodrigues (2016); Santos e Lage (2017); Martines e Rossarolla (2018); Gordo, Bentes e Alameida (2018); Junior, Aguiar e Maia (2019); Schutz, Martinez e Salva (2019); Cardoso e Dias (2016) e Oliveira (2014) foram incluídos na categoria Gênero, 
sexualidade e currículo (16,66\%). Tratam-se de estudos que têm como foco a presença de questões de gênero e sexualidade no currículo escolar. Eles destacam a inclusão das discussões de gênero na formação de professores, nos conteúdos programáticos e nas práticas escolares. Além disso, sinalizam para a preocupação acerca da presença e da ausência de temas relacionados às questões de gênero no currículo escolar?. Tais estudos também problematizam as potencialidades de uma pedagogia e um currículo queer na escola como alternativa para uma formação libertadora e que celebre a diferença a partir do estranhamento do currículo e da não naturalização das experiências e vivências de gênero. Evidencia-se que tais estudos apontam a pedagogia queer, e uma pedagogia feminista, como uma inovação pedagógica.

Na última categoria, intitulada Invisibilidade de gênero ${ }^{8}$, foram incluídos os estudos de Bogossian (2014); Carvalho et al. (2017); Di Gregorio e Silva (2014); Kaplan e Xavier (2018); Santana (2014); Santana et al. (2016) e Vieira e Coelho (2014). Ao lançar luzes às questões de gênero e sexualidade de jovens com deficiência, os estudos problematizam que os corpos com deficiência também são gendrados. Contudo, as vivências de gêneros e de sexualidades desses corós são invisibilizadas.

\section{CONSIDERAÇÕES FINAIS}

Nesse estudo desenvolvemos uma revisão sistematizada da literatura acerca da produção do conhecimento sobre gênero nos periódicos da área de educação, filiados ao Fórum de Editores de Periódicos da Área de Educação - FEPAE/ANPED-Norte/Nordeste. A partir dos critérios de inclusão/exclusão definidos, analisamos 60 estudos publicados, entre 2014 a 2019, na Revista Tempos e Espaços em Educação (40 artigos, 66,66\% do total), Revista Exitus (06 artigos, 10\% do total), Revista Educação \& Formação

\footnotetext{
7 Sobre as discussões sobre currículo ler os trabalhos de Rudd e Goodson (2016), Uljens (2016), Pacheco e Sousa (2016), Morgado (2016), Moreira e Silva Junior (2016), Kovacs e Tinoca (2017), Fino (2016), Sousa (2016), Pedro (2017), Barbosa e Cassiani (2017).

8 Sobre as discussões de deficiência ver os trabalhos de Marques (2019), Girardi, Rechia e Tschoke (2019), Rodrigues e Gai (2016), Oliveira (2014), Boto (2014).
} 
(05 artigos, 8,34\% do total) e Revista Práxis Educacional (09 artigos, 15\% do total). Evidencia-se que, pela alta concentração de estudos explorados nesse levantamento, a Revista Tempos e Espaços em Educação explicita uma maior tendência à divulgação de estudos com foco em fenômenos emergentes das relações entre gênero e educação.

Sobre a abordagem metodológica dos estudos, destacamos que $25 \%$ utilizaram ensaios e pesquisa bibliográfica; 18,33\% (auto)biografia e história de vida; $15 \%$ pesquisa de campo; $11,66 \%$ pesquisa documental; $10 \%$ análise de narrativas; $6,66 \%$ análise fílmica; 3,33\% pesquisa-ação e pesquisa exploratória; 1,66\% análise de imagens, Estudos comparados, pesquisa quantiqualitativa e pesquisa on-line. Esse quadro aponta que os estudos pedagógicos que tomam como foco as questões de gênero têm um largo caminho para desbravar a partir das múltiplas abordagens metodológicas que têm sido pouco utilizadas como é o caso da pesquisa-ação, pesquisa exploratória; análise de imagens, estudos comparados, pesquisa quantiqualitativa e pesquisa on-line.

Acerca da análise dos resultados dos estudos levantados, foi possível fazer emergir sete categorias: Gênero e sexualidade como condicionantes da profissionalização dos sujeitos (04 estudos / 6,67\%); Multiculturalismo e estudos interseccionais ( 11 estudos / 18,33\%); Norma de gênero e corpo (10 estudos ( 16,66\%); Contribuições de pensadores/correntes teóricas para os estudos de gênero (07 estudos / 11,66\%); Concepções acerca da mulher e seu papel social na contemporaneidade (11 estudos / 18,33\%); Gênero, sexualidade e currículo (10 estudos / 16,66\%); e Invisibilidade de gênero (07 estudos / 11,66\%). Esse panorama indica que esse campo de estudos está engajado com questões político-pedagógicas ligadas ao desmonte da sociedade cisheteronormativa, com vistas à construção de uma sociedade igualitária. Trata-se de um esforço científico que têm contribuído para pressionar pela desestabilização de normatizações, classificações e hierarquizações no campo da educação.

Evidencia-se a legítima ausência de estudos que patologizem a questão e busquem compreender as "causas das dissidências de gênero". 
Tal silenciamento afirma que qualquer estudo que tente explicar a diversidade de gênero a partir de variações químicas, hormonais, genéticas ou de qualquer modo biologizantes está na contracorrente dos estudos progressistas que visam contribuir para uma sociedade plural e cada vez mais igualitária. Essa é a espada de Dâmocles para qualquer pesquisador/a sério/a do campo dos estudos de gênero, uma vez que o olhar biologizante iguala seres humanos aos animais, desconsiderando a dimensão subjetiva e condicionando/reduzindo a sexualidade à prática do sexo e as identidades de gênero à comportamentos.

Com o olhar voltado especicamente para o fenômeno na educação institucional, evidencia-se uma pedagogia do gênero baseada num poder hierárquico que se apresenta nas escolas, inicialmente por meio de um olhar vigilante dos/as mais poderosos/as para com os/as menos poderosos/as. Nas escolas do mesmo modo que os esforços de normatização do gênero podem ser empreendidos pelos/as educadores/as, esses sujeitos podem também contribuir para a transgressão da norma e a criação de um cenário de luta em defesa da construção de uma sociedade mais igualitária. Essa pedagogia do gênero se manifesta não apenas no contexto da educação formal, mas se desponta desde as mais tenras idades em todas as instituições sociais das quais os sujeitos fazem parte, a começar pela família.

Como seres históricos, para o ser humano, o Gênero não é estável. Esse, varia de cultura para cultura e de época para época. Ao desconstruir a perspectiva da heteronormatividade e conceber o gênero como um conceito fluido, caminhamos na direção de uma percepção queer da subjetividade. Práticas sexuais e Performances de gênero seriam mais livres. Queer portanto é problematizar. Essa problematização é a via por meio da qual se pode construir uma pedagogia libertadora. Uma pedagogia queer é portanto, uma pedagogia libertadora.

Observa-se que a ausência do debate sobre a questão de gênero no ambiente escolar determina a constituição de visões conceituais distorcidas, como por exemplo a concepção de que a identidade é uma opção. Ao mesmo tempo em que não é possível medir a dor que o preconceito sofrido

Revista Exitus, Santarém/PA, Vol. 10, p. 01-26, e020039, 2020. 
provoca em cada sujeito, é evidente que a opressão sofrida quando as dissidências de gênero se combinam com outros matrcadores sociais da exclusão. Em seus corpos e suas subjetividades o peso histórico de múltiplas exclusões, seja pela cor, pela religião, pelo local de nascimento, pela forma de falar, e por todo e qualquer outro marcador que identifique esse sujeito como classe trabalhadora, solapam a sua existência. Trata-se portanto, da experimentação ne uma série de exclusões e da relação entre essas inclusões, uma vez que o todo é maior que a soma das partes.

A necessidade do debate sobre Gênero e Sexualidade está presente na escola. Contudo, sem ações que visem conscientizar a comunidade escolar dos riscos que o preconceito de gênero pode trazer para crianças e adolescentes que são vítimadas, a escola e o lar podem se transformar em zonas de risco em que, a todo momento, esses sujeitos se sentem ameaçados e por vezes são violentados verbalmente, moralmente, fisicamente e/ou sexualmente. Esses sujeitos passam a descobrir as implicações de confrontar. as normas de gênero, numa caminhada solitária, clandestina e marginalizada. A escola reproduz uma pedagogia do gênero. Assim, ao mesmo tempo em que se configuram como espaços de reflexão e formação do espírito humano, por excelência, elas próprias, as escolas, podem se constituir como palcos de opressão, construção, legitimação e reafirmação de preconceitos socialmente e historicamente construídos.

Obviamente a conclusão dos estudos daqueles/as que desviam da norma de gênero depende de uma série de fatores dentre os quais jamais se poderia excluir o determinante econômico. É possível identificar professores e professoras travestis e transexuais do mesmo modo que estudantes travestis e transexuais, mas esses casos são tão raros que estampam capas de jornais, e pela originalidade do objeto, se tornam temas de análises casos em estudos acadêmicos.

Constata-se assim, que as dissidências de gênero se constituem num tema geralmente tratado com certo desconforto no interior das instituições de ensino e para além desses. Nesse espaço de aprendizagem elas construirão relações sociais entre si e com os demais atores que compõem 
esse cenário. Na dialética da opressão de gênero, superação da condição de oprimido/a não seria a o seu contraditório (o/a opressor/a), mas a busca incessante pela libertação. Sigamos rumo à construção de uma Pedagogia Queer.

\section{REFERÊNCIAS}

ABIB, L. T. et al. Lecturas sobre el cuerpo en la película "Atrapado sin Salida": poder, educación, modernidad y biopolítica. Práxis Educacional, Vitória da Conquista, v. 14, n. 29, p. 198-212, ago. 2018. Disponível em: <http://periodicos2.vesb.br/index.php/praxis/article/view/4106>. Acesso em: 17 abr. 2020. doi: https://doi.org/10.22481/praxis.v14i29.4106.

ALMEIDA, W. R. A. Uniforme escolar e uniformização dos corpos. Revista Tempos e Espaços em Educação, São Cristóvão, v. 10, n. 22, p. 9-22, 2017. Disponível em: <https://seer.ufs.br/index.php/revtee/article/view/6134>. Acesso em: 3 jan. 2020. DOI: https://doi.org/10.20952/revtee.v10i22.6134.

ANJOS, J. P.; CARDOSO, L. R. Hanami ou corpos fogem, vazam, escapam...

Revista Tempos e Espaços em Educação, São Cristóvão, v. 7, n. 14, p. 69-78, 2014. Disponível em: <https://seer.ufs.br/index.php/revtee/article/view/2953>. Acesso em: 3 jan. 2020. DOI: https://doi.org/10.20952/revtee.v0i0.2953.

ARAÚJO, E.; BARROS, V. "Modo Deadline": uma análise sobre o tempo das mulheres académicas. Revista Tempos e Espaços em Educação, São Cristóvão, v. 10, n. 22, p. 173-186, 2017. Disponível em: $<$ https://seer.ufs.br/index.php/revtee/article/view/6440>. Acesso em: 3 jan. 2020. DOI: https://doi.org/10.20952/revtee.v10i22.6440.

ARAÚJO, M. M.; CUNHA, R. M.; ALCÂNTARA, P. B. A Educação Escolar Primária de Mulheres e Homens de Cor Negra (Rio Grande do Norte, 19311948). Práxis Educacional, Vitória da Conquista, v. 13, n. 26, mar. 2018.

Disponível em:

<http://periodicos2.vesb.br/index.php/praxis/article/view/2831>. Acesso em: 17 abr. 2020. DOI: https://doi.org/10.22481/praxis.v13i26.2831.

BASTOS, L.; EITERER, C. L. Reconfiguração das relações de gênero e cotidiano das mulheres educandas da EJA. Educação \& Formação, Fortaleza, v. 2, n. 6 set/dez, p. 42-53, 1 set. 2017. Disponível em:

<https://revistas.uece.br/index.php/redufor/article/view/158>. Acesso em: 17 abr. 
BARBOSA, A.; CASSIANI, S. Circulação de sentidos da prática como componente curricular na licenciatura em Ciências biológicas. Educação \& Formação, Fortaleza, v. 2, n. 4 jan/abr, p. 52-71, 2 jan. 2017. Disponível em: <https://revistas.uece.br/index.php/redufor/article/view/123>. Acesso em: 17 abr. DOI: https://doi.org/10.25053/edufor.v2i4.1920.

BAROLLI, E.; VILLANI, A. A formação de professores de Ciências no Brasil como campo de disputas. Revista Exitus, Santarém, v. 5, n. 1, p. 72-90, 2016. Disponível em:

$<$ http://ufopa.edu.br/portaldeperiodicos/index.php/revistaexitus/article/view 192>. Acesso em: 12 mai. 2020.

BANFIELD, G.; HADUNTZ, H.; MAISURIA, A. The (im)possibility of the intellectual worker inside the neoliberal university. Educação \& Formação, Fortaleza, v. 1, n. 3 set/dez, p. 3-19, 1 set. 2016. Disponível em: <https://revistas.uece.br/index.php/redufor/article/view/110>. Acesso em: 17 abr. DOI: https://doi.org/10.25053/edufor.vli3.1974.

BLANCHARD, M.; MUZÁS, M. D. La influencia de las narraciones en la construcción de la identidad de las mujeres educadoras en Portugal y España. Práxis Educacional, Vitória da Conquista, v. 12, n. 21, p. 247-269, set. 2015. Disponível em:

<http://periodicos2.uesb.br/index.php/praxis/article/view/870>. Acesso em: 17 abr. 2020.

BECKER, S.; OLIVEIRA, E. A. Educação e direitos para (in)humanos? Desafios e reflexões sobre os dilemas de LGBTs perante o discurso jurídico brasileiro.

Revista Tempos e Espaços em Educação, São Cristóvão, v. 9, n. 19, p. 163180, 2016. Disponível em:

$<$ https://seer.ufs.br/index.php/revtee/article/view/5603>. Acesso em: 3 jan. 2020. DOI: https://doi.org/10.20952/revtee.v9i19.5603.

BEGO, A. Políticas públicas e formação de professores sob a perspectiva da racionalidade comunicativa: da ingerência tecnocrata à construção da autonomia profissional. Educação \& Formação, Fortaleza, v. 1, n. 2 mai/ago, p. 3-24, 2 maio, 2016. Disponível em: <https://revistas.uece.br/index.php/redufor/article/view/98>. Acesso em: 17 abr. DOI: https://doi.org/10.25053/edufor.vli2.1864.

BOGOSSIAN, T. "Já pensou Pedro com um cabelão de Maria Chiquinha! Não combina, né??!". Geografia e gênero na educação infantil. Revista Tempos e Espaços em Educação, São Cristóvão, v. 7, n. 12, p. 169-186, 2014. Disponível em: <https://seer.ufs.br/index.php/revtee/article/view/2963>. Acesso em: 3 jan. 2020. DOI: https://doi.org/10.20952/revtee.v0i0.2963. 
BOTO, C. Civilizar a infância na Renascença: estratégia de distinção de classe. Revista Tempos e Espaços em Educação, São Cristóvão, v 4, n. 6 , jan./jun., 2014. Disponível em:

<https://seer.ufs.br/index.php/revtee/article/view/2208>. Acesso em: 17 abr. 2020

CANOTILHO, A. P.; ARAUJO, N. F.; DE OLIVEIRA, S. M. T. A contribuição da escola para a emancipação das mulheres. Revista Tempos e Espaços em Educação, São Cristóvão, v. 7, n. 14, p. 91-102, 2014. Disponível em: <https://seer.ufs.br/index.php/revtee/article/view/2957>. Acesso em: 3 jan. 2020. DOI: https://doi.org/10.20952/revtee.v0i0.2957.

CARDOSO, H. M. Gênero, sexualidade e escola: contribuições da teorização de Foucault. Revista Tempos e Espaços em Educação, São Cristóvão, v. 11, n. 1, p. 319-332, 2019. Disponível em: <https://seer.ufs.br/index.php/revtee/article/view/9652>. Acesso em: 3 jan. 2020. DOI: https://doi.org/10.20952/revtee.v1 1i01.9652.

CARDOSO, H. M.; DIAS, A. F. Representações sobre corpo, gênero e sexualidades de estudantes das licenciaturas do Instituto Federal de Sergipe, campus Aracaju. Práxis Educacional, Vitória da Conquista, v. 13, n. 24, p. 7694, 2016. Disponível em:

<http://periodicos2.uesb.br/index.php/praxis/article/view/930>. Acesso em: 6 jan. 2020. DOI: https://doi.org/10.22481/praxis.v13i24.930.

CARVALHO, M. E. P. et al. Origins and challenges of gender studies centers in higher education in NorthERN and Northeastern Brazil. Revista Tempos e Espaços em Educação, São Cristóvão, v. 10, n. 21, p. 163-176, 2017. Disponível em: <https://seer.ufs.br/index.php/revtee/article/view/6340>. Acesso em: 3 jan. 2020. DOl: https://doi.org/10.20952/revtee.v10i21.6340.

CORRADINI, S. N.; MIZUKAMI, M. G. Formação docente: o profissional da sociedade contemporânea. Revista Exitus, Santarém, v. 1, n. 1, p. 53-62, 2017. Disponível em:

<http://ufopa.edu.br/portaldeperiodicos/index.php/revistaexitus/article/view /205>. Acesso em: 12 mai. 2020.

COOPER, H. Research synthesis and meta-analysis: a step-by-step approach. 3. ed. Thousand Oaks: Sage, 2010.

COSTA, P. R. S. M.; MACARRO, M. J. M. Los aspectos educativos de la Ley Orgánica 01/2004 de 28 de diciembre, de medidas de protección integral contra la violencia de género. Revista Tempos e Espaços em Educação, São Cristóvão, v. 9, n. 20, p. 111-120, 2016. Disponível em: <https://seer.ufs.br/index.php/revtee/article/view/5900>. Acesso em: 3 jan. 2020. DOI: https://doi.org/10.20952/revtee.v9i20.5900. 
COUTO, A. S.; CRUZ, M. H. S. Inserção de gênero no currículo de História e a formação para o trabalho docente. Revista Tempos e Espaços em

Educação, São Cristóvão, v. 10, n. 23, p. 249-262, 2017. Disponível em:

$<$ https://seer.ufs.br/index.php/revtee/article/view/6764> . Acesso em: 3 jan. 2020. DOI: https://doi.org/10.20952/revtee.v10i23.6764.

CRUZ, M. H. S. A crítica feminista à ciência e contribuição à pesquisa nas Ciências Humanas. Revista Tempos e Espaços em Educação, São Cristóvão, v. 7, n. 14, p. 15-28, 2014. Disponível em:

<https://seer.ufs.br/index.php/revtee/article/view/2949>. Acesso em: 3 jan. 2020. DOI: https://doi.org/10.20952/revtee.v0i0.2949.

DARSIE, C. et al. A produção da mulher ideal no filme Ela: Questões sobre gênero e performatividade no cinema. Educação \& Formação, Fortaleza, v. 3, n. 9 set/dez, p. 189-203, 3 set. 2018. Disponível em: <https://revistas.uece.br/index.php/redufor/article/view/852>. Acesso em: 3 jan. 2020.

DIAS, A. F. Como as escolas educam corpos nas práticas pedagógicas?.

Revista Tempos e Espaços em Educação, São Cristóvão, v. 7, n. 12, p. 103112, 2014. Disponível em:

<https://seer.ufs.br/index.php/revtee/article/view/2958>. Acesso em: 3 jan. 2020. DOI: https://doi.org/10.20952/revtee.v0i0.2958.

DIAS, A. F. et al. Schooling and subversions of gender. Revista Tempos e Espaços em Educação, São Cristóvão, v. 10, n. 22, p. 83-92, 2017. Disponível em: <https://seer.ufs.br/index.php/revtee/article/view/6433>. Acesso em: 3 jan. 2020. DOI: https://doi.org/10.20952/revtee.v10i22.6433.

DIAS, A. F.; AMORIM, S. Body, gender and sexuality in teacher training: a meta-analysis. Educação em Revista, Curitiba, n. 56, p. 193-206, 2015.

Disponível em:

<http://www.scielo.br/scielo.php? script=sci_arttext\&pid=s010440602015000200193\&lng=en\&nrm=isso >. Acesso em: 6 jan. 2020. DOl: http://dx.doi.org/10.1590/0104-4060.40998

DIAS, A. F.; MENEZES, C. A. A. Que inovação pedagógica a pedagogia queer propõe ao currículo escolar?. Revista Tempos e Espaços em Educação, São Cristóvão, v. 10, n. 23, p. 37-48, 2017. Disponível em: <https://seer.ufs.br/index.php/revtee/article/view/7443>. Acesso em: 3 jan. 2020. DOI: https://doi.org/10.20952/revtee.v10i23.7443.

DIAS, A. F.; OLIVEIRA, D. A. As abordagens de corpo, gênero e sexualidades no projeto político-pedagógico em um Colégio Estadual de Aracaju, SE.

Holos, Natal, v. 3, p. 259-271, 2015. Disponível em:

<http://www2.ifrn.edu.br/ojs/index.php/holos/article/view/3084> . Acesso em: 06 jan. 2020. DOI: https://doi.org/10.15628/holos.2015.3084. 
DIAS, A. F.; OLIVEIRA, D. A.; SANTOS, M. S. Uma revisão sistematizada da produção do conhecimento sobre corpo, gênero, sexualidades na educação. Revista Temas em Educação, João Pessoa, v. 27, n. 2, p. 119-133, 2018. Disponível em: <https://doi.org/10.22478/ufpb.23597003.2018v27n2.24814>. Acesso em: 10 jan. 2020.

DI GREGORIO, M. F.; SILVA, K. N. Gênero e sexualidade no lócus família/escola: incursões deflagradas à não heterossexualidade e os desafios para a cidadania reconhecida. Revista Tempos e Espaços em Educação, São Cristóvão, v. 7, n. 12, p. 79-90, 2014. Disponível em: <https://seer.ufs.br/index.php/revtee/article/view/2954>. Acesso em: 3 jan. 2020. DOI: https://doi.org/10.20952/revtee.v0i0.2954.

DONATO, A.; TONELLI, L. A resistência do corpo. Revista Tempos e Espaços em Educação, São Cristóvão, v. 12, n. 28, p. 49-62, 2019. Disponível em: <https://seer.ufs.br/index.php/revtee/article/view/10164>. Acesso em: 3 jan. 2020. DOI: https://doi.org/10.20952/revtee.v12i28.10164.

DUBET, F. A escola "embaraçada" com a educação mista. Revista Tempos e Espaços em Educação, São Cristóvão, v. 11, n. 25, p. 9-20, 2018. Disponível em: <https://seer.ufs.br/index.php/revtee/article/view/8379>. Acesso em: 3 jan. 2020. DOl: https://doi.org/10.20952/revtee.v1 1i25.8379.

EUGÊNIO, B. G.; LIMA, A. O. Imagens de negros e negras no livro didático de História dos anos iniciais do ensino fundamental. Revista Tempos e Espaços em Educação, São Cristóvão, v. 8, n. 16, p. 247-256, 2015. Disponível em: <https://seer.ufs.br/index.php/revtee/article/view/3964>. Acesso em: 3 jan. 2020. DOI: https://doi.org/10.20952/revtee.v0i0.3964.

FERREIRA, M. M. Relações de classe e gênero na escola: revisitando conceitos de igualdade, desigualdade, diferença, classe e gênero. Revista Tempos e Espaços em Educação, São Cristóvão, v. 7, n. 14, p. 57-68, 2014. Disponível em: <https://seer.ufs.br/index.php/revtee/article/view/2952>. Acesso em: 3 jan. 2020. DOI: https://doi.org/10.20952/revtee.v0i0.2952.

FIGUEIREDO FILHO, D. B. et al. O que é, para que serve e como se faz uma meta-análise?. Revista Teoria \& Pesquisa, São Carlos, v. 23, n. 2, p. 205-228, 2014.

FINO, C. N. Inovação Pedagógica e Ortodoxia Curricular. Revista Tempos e Espaços em Educação, São Cristóvão, v. 9, n. 18, p. 13-22, 14 abr. 2016. Disponível em: <https://seer.ufs.br/index.php/revtee/article/view/4959>. Acesso em: 17 abr. 2020.

FRANÇA, F. G. R.; FERRARI, A. Mais do que professores/as, professores/as homossexuais na escola. Revista Tempos e Espaços em Educação, São 
Cristóvão, v. 9, n. 20, p. 41-52, 2016. Disponível em: $<$ https://seer.ufs.br/index.php/revtee/article/view/5894>. Acesso em: 3 jan. 2020. DOI: https://doi.org/10.20952/revtee.v9i20.5894.

GALAK, E. Pedagogías del cuerpo y del carácter en la "Revista de Educación" durante la gobernación de José Luís Cantilo (Buenos Aires, 19221926). Revista Tempos e Espaços em Educação, São Cristóvão, v. 10, n. 21, p. 149-162, 2017. Disponível em: $<$ https://seer.ufs.br/index.php/revtee/article/view/6339>. Acesso em: 3 jan. 2020. DOI: https://doi.org/10.20952/revtee.v10i21.6339.

GENÚ, M. A abordagem da ação crítica e a epistemologia da práxis pedagógica. Educação \& Formação, Fortaleza, v. 3, n. 9 set/dez, p. 55-70, 3 set. 2018. Disponível em: <https://revistas.uece.br/index.php/redufor/article/view/856>. DOI: https://doi.org/10.25053/redufor.v3i9.856.

GIRARDI, V.; RECHIA, S.; TSCHOKE, A. Acessibilidade formacional: a percepção profissional na inclusão da pessoa com deficiência intelectual no lazer. Educação \& Formação, Fortaleza, v. 5, n. 13jan/abr, p. 95-112, 9 dez. 2019. Disponível em: <https://revistas.uece.br/index.php/redufor/article/view/1180>. DOI: https://doi.org/10.25053/redufor.v5i13.1180.

GORDO, M. E. S. C; BENTES, L. M. N; ALAMEIDA, R. O. Significações do corpo na escola de aplicação da UFPA. Revista Exitus, Santarém, v. 8, n. 2, p. 329357, 2018. Disponível em:

<http://www.ufopa.edu.br/portaldeperiodicos/index.php/revistaexitus/article /view/540>. Acesso em: 17 abr. de 2020. DOI: http://dx.doi.org/10.24065/2237$\underline{9460.2018 \mathrm{v} 8 \mathrm{n} 2 \mathrm{ID} 540}$

GUZZI, J. 21 Gramos: el amor como epifenómeno de la tensión cuerpo-alma. Revista Tempos e Espaços em Educação, São Cristóvão, v. 12, n. 29, p. 213226, 2019. Disponível em:

<https://seer.ufs.br/index.php/revtee/article/view/9514>. Acesso em: 3 jan. 2020. DOI: https://doi.org/10.20952/revtee.v12i29.9514.

JUNGES, F. C.; KETZER, C.; OLIVEIRA, V. M. Formação continuada de professores: Saberes ressignificados e práticas docentes transformadas.

Educação \& Formação, Fortaleza, v. 3, n. 9 set/dez, p. 88-101, 2018. Disponível em: <https://revistas.uece.br/index.php/redufor/article/view/858>. Acesso em: 3 jan. 2020. DOI: https://doi.org/10.25053/redufor.v3i9.858.

LIMA, J.; SANTOS, G. Valores, educação infantil e desenvolvimento moral: concepções dos professores. Educação \& Formação, Fortaleza, v. 3, n. 8 mai/ago, p. 153-170, 2018. Disponível em: 
<https://revistas.uece.br/index.php/redufor/article/view/275>. Acesso em: 3 jan. 2020. DOI: https://doi.org/10.25053/redufor.v3i8.275.

LUCENA, S.; OLIVEIRA, J. M. A. Culturas digitais na educação do Século XXI. Revista Tempos e Espaços em Educação, p. 35-44, 30 dez. 2014.

Disponível em: https://seer.ufs.br/index.php/revtee/article/view/3449

KOVACS, H.; TINOCA, L. Unfreeze the pedagogies: introduction of a new innovative measure in Portugal. Revista Tempos e Espaços em Educação, São Cristóvão, v. 10, n. 23, p. 73-86, 2017. Disponível em: $<$ https://seer.ufs.br/index.php/revtee/article/view/7446>. Acesso em: 3 jan. 2020.

KAPLAN, C. V.; XAVIER, N. R. As infâncias na literatura latino-americana: quais os lugares da menina e da mulher negras?. Revista Tempos e Espaços em Educação, São Cristóvão, v. 11, n. 25, p. 111-126, 2018. Disponível em: $<$ https://seer.ufs.br/index.php/revtee/article/view/8797>. Acesso em: 3 jan. 2020. DOI: https://doi.org/10.20952/revtee.v1 li25.8797.

MARTINES, E. A. L. M; ROSSAROLLA, J. N. Sexo e sexualidade: tabu, polêmica ou conceitos polissêmicos? Reflexões sobre/para a formação de educadores. Revista Exitus, Santarém, v. 8, n. 2, p. 273-299, 2018. Disponível em:

<http://www.ufopa.edu.br/portaldeperiodicos/index.php/revistaexitus/article /view/537>. Acesso em: 17 abr. de 2020. DOI: http://dx.doi.org/10.24065/22379460.2018v8n2ID537.

MARQUES, L. Reações familiares diante da criança em situação de deficiência. Educação \& Formação, Fortaleza, v. 4, n. 12 set/dez, p. 67-81, 2019. Disponível em:

<https://revistas.uece.br/index.php/redufor/article/view/912>. Acesso em: 17 abr. de 2020. DOI: https://doi.org/10.25053/redufor.v4i12.912.

MIRANDA, C. Pesquisadoras negras na docência do ensino superior: uma análise a partir da perspectiva (auto)biográfica. Práxis Educacional, Vitória da Conquista, v. 14, n. 30, p. 393-414, out. 2018. Disponível em:

<http://periodicos2.vesb.br/index.php/praxis/article/view/4374>. Acesso em:

17 abr. 2020. DOI: https://doi.org/10.22481/praxis.v14i30.4374.

MORAIS, A. B. A.; CARVALHO, M. E. P. Institucionalização dos estudos de gênero na universidade: uma análise a partir de narrativas de acadêmicas feministas. Revista Tempos e Espaços em Educação, São Cristóvão, v. 8, n. 17, p. 235-236, 2015. Disponível em:

<https://seer.ufs.br/index.php/revtee/article/view/4526>. Acesso em: 3 jan. 2020. DOI: https://doi.org/10.20952/revtee.v8i17.4526. 
MORORÓ, L. A influência da formação continuada na prática docente. Educação \& Formação, Fortaleza, v. 2, n. 4 jan/abr, p. 36-51, 2017. Disponível em: <https://revistas.uece.br/index.php/redufor/article/view/122>. Acesso em: 17 abr. de 2020. DOl: https://doi.org/10.25053/edufor.v2i4.1961.

MOREIRA, A. F.; SILVA JÚNIOR, P. M. DA. Currículo, Transgressão e Diálogo: quando Outras Possibilidades se Tornam Necessárias. Revista Tempos e Espaços em Educação, São Cristóvão, v. 9, n. 18, p. 45-54, 11. Disponivel em: <https://seer.ufs.br/index.php/revtee/article/view/4962>. Acesso em: 17 abr. de 2020.

MONTENEGRO, M. S. et al. Narrativas de mulheres presidiárias sobre o tempo vivido no ambiente carcerário: entre Chronos e Kairós. Práxis Educacional, Vitória da Conquista, v. 15, n. 35, p. 293-309, out. 2019. Disponível em: <http://periodicos2.uesb.br/index.php/praxis/article/view/5683>. Acesso em: 17 abr. 2020. DOI: https://doi.org/10.22481/praxisedu.v15i35.5683.

MORGADO, J. C. O professor como decisor curricular: de ortodoxo a cosmopolita. Revista Tempos e Espaços em Educação, São Cristóvão, v. 9, n. 18, p. 55-64, 2016. Disponivel em:

<https://seer.ufs.br/index.php/revtee/article/view/4964>. Acesso em: 17 abr. de 2020.

NUNES, E. T.; SILVA, I. P.; MERCADO, L. P. Levantamento dos temas TIC e EAD nos periódicos qualis. Informática na educação: teoria \& prática, Porto Alegre, v. 19, n. 3 set/dez, 2016. Disponível em: < https://www.seer.ufrgs.br/InfEducTeoriaPratica/article/view/62116>. Acesso em: 17 abr. 2020. DOI: https://doi.org/10.22456/1982-1654.62116.

OLIVEIRA, L.; MARTINIAK, V. L. Liberdade, igualdade e democracia: o ideário republicano e a educação das mulheres no início do século XX no Brasil.

Educação \& Formação, Fortaleza, v. 3, n. 9 set/dez, p. 159-176, 2018. <https://revistas.uece.br/index.php/redufor/article/view/861>. Acesso em: 17 abr. de 2020.

OLIVEIRA, A P. Gênero, sexualidade e diversidade no currículo escolar: a experiência do papo sério em Santa Catarina. Práxis Educacional, Vitória da Conquista, v. 11, n. 18, p. 131-151, dez. 2014. Disponível em:

<http://periodicos2.vesb.br/index.php/praxis/article/view/804>. Acesso em: 17 abr. 2020.

OLIVEIRA, J. B. G. A perspectiva da inclusão escolar da pessoa com deficiência no Brasil: um estudo sobre as políticas públicas. Revista Tempos e Espaços em Educação, São Cristóvão, v 4, n. 6, jan./jun., 2014. Disponível em: <https://seer.ufs.br/index.php/revtee/article/view/2250>. Acesso em: 17 abr. de 2020. 
OLIVEIRA, A. L.; GUIMARÃES, M. Da Práxis Participativa À Educação Ambiental Crítica: Análises De Propostas Formativas De Educadores Ambientais Da Baixada Fluminense. Revista Tempos e Espaços em Educação, v. 5, n. 8, 2014. Disponível em: https://seer.ufs.br/index.php/revtee/article/view/2271.

OLIVEIRA, A. M. DE; GEREVINI, A. M.; STROHSCHOEN, A. A. G. Diário de bordo: uma ferramenta metodológica para o desenvolvimento da alfabetização científica. Revista Tempos e Espaços em Educação, São Cristóvão, v. 10, n. 22, p. 119-132, 2017. Disponível em: <https://seer.ufs.br/index.php/revtee/article/view/6429>. Acesso em: 17 abr. de 2020. DOI: https://doi.org/10.20952/revtee.v10i22.6429.

PAIVA, E. A. F; MOMMA-BARDELA, A. M. Políticas Públicas de prevenção à violência sexual: direitos da criança à infância em construção. Revista Exitus, Santarém, v. 4, n. 2, p. 69-86, 2016. Disponível em:

<http://www.ufopa.edu.br/portaldeperiodicos/index.php/revistaexitus/article /view/115>. Acesso em: 17 abr. de 2020.

PACHECO, J. A.; SOUSA, J. O (pós) crítico na Desconstrução Curricular. Revista Tempos e Espaços em Educação, São Cristóvão, v. 9, n. 18, p. 65-74, 2016. Disponível em: <https://seer.ufs.br/index.php/revtee/article/view/4971>. Acesso em: 17 abr. de 2020.

PEDRO, N. Ambientes educativos inovadores: o estudo do fator espaço nas 'salas de aula do futuro' portuguesas. Revista Tempos e Espaços em Educação, São Cristóvão, v. 10, n. 23, p. 99-108, 2017. Disponível em: $<$ https://seer.ufs.br/index.php/revtee/article/view/7448>. Acesso em: 17 abr. de 2020. DOI: https://doi.org/10.20952/revtee.v10i23.7448.

PINTO, É. J. S.; CARVALHO, M. E. P.; RABAY, G. As relações de gênero nas escolhas de cursos superiores. Revista Tempos e Espaços em Educação, São Cristóvão, v. 10, n. 22, p. 47-58, 2017. Disponível em: $<$ https://seer.ufs.br/index.php/revtee/article/view/6173>. Acesso em: 3 jan. 2020. DOI: https://doi.org/10.20952/revtee.v10i22.6173.

PORTO, R.; GALVÃO, F. D. De Slutwalk à Marcha das Vadias: o imperativo dos feminismos em Natal (RN). Revista Tempos e Espaços em Educação, São Cristóvão, v. 9, n. 19, p. 147-162, 2016. Disponível em: $<$ https://seer.ufs.br/index.php/revtee/article/view/5602>. Acesso em: 3 jan. 2020. DOI: https://doi.org/10.20952/revtee.v9i19.5602.

PREINFALK-FERNÁNDEZ, M. L. La Educación sexual en el sistema educativo formal costarricense. Revista Tempos e Espaços em Educação, São Cristóvão, v. 9, n. 19, p. 103-112, 2016. Disponível em: https://seer.ufs.br/index.php/revtee/article/view/5599. Acesso em: 3 jan. 2020. DOI: https://doi.org/10.20952/revtee.v9i19.5599. 
RIOS, P. P.; CARDOSO, H. M.; DIAS, A. F. Concepções de gênero e sexualidade d@s docentes do curso de licenciatura em Pedagogia: por um currículo Queer. Educação \& Formação, Fortaleza, v. 3, n. 8, p. 98-117, 2018. Disponível em: <https://revistas.uece.br/index.php/redufor/article/view/272>. Acesso em: 10 jan. 2020. DOI: https://doi.org/10.25053/redufor.v3i8.272.

RIOS, P. P. S; DIAS, A. F; BRAZÃO, J. P. G. "Lembro-me de querer andar durinho, como se diz que homem deve ser": a construção do corpo gay na escola. Revista Exitus, Santarém, v. 9, n. 4, p. 775-804, 2019. Disponível em: <http://www.ufopa.edu.br/portaldeperiodicos/index.php/revistaexitus/article /view/1033>. Acesso em: 17 abr. de 2020. DOI: http://dx.doi.org/10.24065/2237-9460.2019v9n4ID1033

RODRIGUES, E.; GAI, D. Atendimento educacional especializado e atelier pedagógico (entre deficiência potencial e arte potencial). Educação \& Formação, Fortaleza, v. 1, n. 3 set/dez, p. 125-139, 2016. Disponível em: <https://revistas.uece.br/index.php/redufor/article/view/117>. Acesso em: 17 abr. de 2020. DOl: https://doi.org/10.25053/edufor.v1i3.1620.

RODRIGUES, D. S.; FARO, L. C. A. Entre fronteiras semoventes: a constituição do feminino das filhas de lemanjá. Revista Tempos e Espaços em Educação, São Cristóvão, v. 12, n. 29, p. 61-80, 2019. Disponível em: <https://seer.ufs.br/index.php/revtee/article/view/11022>. Acesso em: 3 jan. 2020. DOI: https://doi.org/10.20952/revtee.v12i29.11022.

RODRIGUES, L. Transgredir para empoderar: o empoderamento das jovens mulheres pela educação. Revista Tempos e Espaços em Educação, São Cristóvão, v. 9, n. 18, p. 91-98, 2016. Disponível em: <https://seer.ufs.br/index.php/revtee/article/view/4967>. Acesso em: 3 jan. 2020. DOI: https://doi.org/10.20952/revtee.v9i18.4967.

RUDD, T.; GOODSON, I. F. Refraction as a tool for understanding action and educational orthodoxy and transgression. Revista Tempos e Espaços em Educação, São Cristóvão, v. 9, n. 18, p. 99-110, 2016. Disponível em: <https://seer.ufs.br/index.php/revtee/article/view/4968>. Acesso em: 21 jan. 2020. DOI: https://doi.org/10.20952/revtee.v9i18.4968.

SANTANA, A. M. Gênero, sexualidade e educação: perspectivas em debate. Revista Tempos e Espaços em Educação, São Cristóvão, v. 7, n. 12, p. 151 168, 2014. Disponível em: <https://seer.ufs.br/index.php/revtee/article/view/2962>. Acesso em: 3 jan. 2020. DOI: https://doi.org/10.20952/revtee.v0i0.2962.

SANTANA, J. V. J. et al. Constituindo gêneros: sobre a produção de masculinidades e feminilidades na educação infantil. Revista Tempos e Espaços em Educação, São Cristóvão, v. 9, n. 20, p. 63-80, 2016. Disponível 
em: <https://seer.ufs.br/index.php/revtee/article/view/5896>. Acesso em: 3 jan. 2020. DOI: https://doi.org/10.20952/revtee.v9i20.5896.

SANTOS, A. C.; FELDENS, D. G. Vozes do triunfo: narrativas de si de professoras da educação básica. Revista Tempos e Espaços em Educação, São Cristóvão, v. 11, n. 1, p. 379-392, 2019. Disponível em: $<$ https://seer.ufs.br/index.php/revtee/article/view/9666>. Acesso em: 3 jan. 2020. DOI: https://doi.org/10.20952/revtee.v1 1i01.9666.

SANTOS, É. S.; LAGE, A. C. Gênero e diversidade sexual na educação básica: um olhar sobre o componente curricular Direitos Humanos e Cidadania da rede de ensino de Pernambuco. Revista Tempos e Espaços em Educação, São Cristóvão, v. 10, n. 22, p. 69-82, 2017. Disponível em: $<$ https://seer.ufs.br/index.php/revtee/article/view/6042>. Acesso em: 3 jan. 2020. DOI: https://doi.org/10.20952/revtee.v10i22.6042.

SANTOS, W. J.; SILVA, I. P. Revisão acerca dos temas alfabetização científica e ensino por investigação. Educa: Revista Multidisciplinar em Educação, Porto Velho, v. 5, n. 12, p. 138-150, 2018. Disponível em: <http://www.periodicos.unir.br/index.php/educa/article/view/3344>. Acesso em: 22 jan. 2020. DOI: http://dx.doi.org/10.26568/2359-2087.2018.3344.

SANTOS, A. F.; SILVA, I. P. Levantamento acerca do tema "dispositivos móveis" em revistas e anais de eventos brasileiros da área de educação em ciências e ensino de física (2007-2016). Revista Cocar, Belém, v. 13, n. 27, p. 660-684, 2019. Disponível em: <https://paginas.uepa.br/seer/index.php/cocar/article/view/2862>. Acesso em: 22 jan. 2020.

SARAT, M.; CAMPOS, M. I. Gênero, sexualidade e infância: (con)formando meninas. Revista Tempos e Espaços em Educação, São Cristóvão, v. 7, n. 14 , p. 45-56, 2014. Disponível em: < <https://seer.ufs.br/index.php/revtee/article/view/2951>. Acesso em: 3 jan. 2020. DOI: https://doi.org/10.20952/revtee.v0i0.2951.

SCHUTZ, L. W; MARTINEZ, L. S; SALVA, S. discutindo concepções sobre sexualidade infantil: um tema delicado. Práxis Educacional, Vitória da Conquista, v. 15, n. 31, p. 452-470, jan. 2019. Disponível em:

<http://periodicos2.vesb.br/index.php/praxis/article/view/4682>. Acesso em: 17 abr. 2020. DOI: https://doi.org/10.22481/praxis.v15i31.4682.

SILVA JUNIOR, P. M.; IVENICKI, A. Entre sexualidades, masculinidades e raça: contribuições do multi/interculturalismo para a prática pedagógica. Revista Tempos e Espaços em Educação, São Cristóvão, v. 12, n. 29, p. 125-144, 2019. Disponível em: <https://seer.ufs.br/index.php/revtee/article/view/9326>. Acesso em: 3 jan. 2020. DOl: https://doi.org/10.20952/revtee.v12i29.9326. 
SILVA JUNIOR, E. E. 'Os três ensaios sobre a teoria da sexualidade' sob a luz da cultura de massa: reflexões sobre o pensamento de Freud na contemporaneidade. Revista Exitus, Santarém, v. 5, n. 1, p. 122-140, 2016. Disponível em:

<http://www.ufopa.edu.br/portaldeperiodicos/index.php/revistaexitus/article Lview/97>. Acesso em: 17 abr. de 2020.

SILVA, A. S; PINHEIRO, B. C. S. Químicxs negros e negras do século XX e o racismo institucional nas ciências. Revista Exitus, Santarém, v. 9, n. 4, p. 121 146, 2019. Disponível em: <http://www.ufopa.edu.br/portaldeperiodicos/index.php/revistaexitus/article /view/1007>. Acesso em: 17 abr. de 2020. DOI: http://dx.doi.org/10.24065/2237-9460.2019v9n4ID1007.

SILVA, I. P. Em busca de significados para a expressão "Ideologia de Gênero". Educação em Revista, Belo Horizonte, v. 34, 2018. Disponível em: <https://www.scielo.br/pdf/edur/v34/1982-6621-edur-34-e190810.pdf>. Acesso em: 12 mai. 2020. DOI: https://doi.org/10.1590/0102-4698190810

SILVA, I. P; DIAS, A. F.; RIOS, P. Os estudos de gênero na Revista Tempos e Espaços em Educação: uma revisão sistematizada. Educação \& Formação, Fortaleza, v. 5, 2020. Disponível em: <https://revistas.uece.br/index.php/redufor/article/view/2495>. Acesso em: 12 mai. 2020. DOl: https://doi.org/10.25053/redufor.v5i14mai/ago.2495

SILVA, I. P.; MAGALHÃES, M. S.; SILVA, S. A. O filme "O espanta tubarões" e o debate sobre diversidade sexual e de gênero na escola. Revista EDaPECI, São Cristovão, v. 19, n. 1, p. 86-94, 2019. Disponível em: <https://seer.ufs.br/index.php/edapeci/article/view/9374>. Acesso em: 12 mai. 2020. DOI: https://doi.org/10.29276/redapeci.2019.19.19374.86-94

SILVA, I. P.; MERCADO, L. P. Revisão sistemática de literatura acerca da experimentação virtual no ensino de Física. Ensino \& Pesquisa, Curitiba, v. 7 , n. 1, 2019. Disponível em:

<http://periodicos.unespar.edu.br/index.php/ensinoepesquisa/article/view/2 381>. Acesso em: 12 mai. 2020.

SILVA, I. P.; MERCADO, L. P. Levantamento de dados acerca do tema "experimentação mediada por interfaces digitais"(2005-2015). Revista

Paidéi@-Revista Científica de Educação a Distância, Santos, v. 10, n. 17, 2018. Disponível em:

<https://periodicos.unimesvirtual.com.br/index.php/paideia/article/view/829 >. Acesso em: 12 mai. 2020.

SILVA, I. P.; MERCADO, L. P. Levantamento dos temas TIC e EAD na biblioteca virtual Educ@. Cadernos de Pesquisa (FCC), São Paulo, v. 45, n. 158, p. $970-$ 988, 2015. Disponível em: <https://www.scielo.br/pdf/cp/v45n158/1980-5314- 
cp-45-158-00970.pdf>. Acesso em: 3 jan. 2020. DOI: https://doi.org/10.1590/198053143367.

SILVA, I. P.; SILVA, A. T. O tema "experimentos virtuais" nos anais dos eventos brasileiros de ensino de Física (2005-2014). Revista de Ensino de Ciências e Matemática (RENCIMA), São Paulo, v. 8, n. 1, p. 137-154, 2017. Disponível em: <http://revistapos.cruzeirodosul.edu.br/index.php/rencima/article/view/1172 >. Acesso em: 3 jan. 2020. DOl: https://doi.org/10.26843/rencima.v8i1.1172.

SILVA, M. A. C. Formação docente: do infinito ao particular! Narrativas sobre gênero, raça e religião. Revista Tempos e Espaços em Educação, São Cristóvão, v. 7, n. 12, p. 125-136, 2014. Disponível em: <https://seer.ufs.br/index.php/revtee/article/view/2960>. Acesso em: 3 jan. 2020. DOI: https://doi.org/10.20952/revtee.v0i0.2960.

SILVA, M. M. T.; TAVARES, C. Mulheres na luta: participação de mulheres nas ocupações de 2016 na Universidade Federal de Pernambuco. Revista Tempos e Espaços em Educação, São Cristóvão, v. 11, n. 27, p. 41-60, 2018. Disponível em: <https://seer.ufs.br/index.php/revtee/article/view/7409> . Acesso em: 3 jan. 2020. DOI: https://doi.org/10.20952/revtee.v1 li27.7409.

SOUZA, L. P. Educação, gênero e raça: mapeando algumas desigualdades. Revista Tempos e Espaços em Educação, São Cristóvão, v. 7, n. 12, p. 113124, 2014. Disponível em:

<https://seer.ufs.br/index.php/revtee/article/view/2959>. Acesso em: 3 jan. 2020. DOI: https://doi.org/10.20952/revtee.v0i0.2959.

SOUZA, J. S. DE; BONILLA, M. H. S. A cultura digital na formação de professores. Revista Tempos e Espaços em Educação, p. 23-34, 30 dez. 2014. Disponível em: https://seer.ufs.br/index.php/revtee/article/view/3447.

SOUSA, J. M. Repensar o currículo como emancipador. Revista Tempos e Espaços em Educação, São Cristóvão, v. 9, n. 18, p. 111-120, 2016. Disponível em: <https://seer.ufs.br/index.php/revtee/article/view/4969>. Acesso em: 17 abr. de 2020. DOI: https://doi.org/10.20952/revtee.v9i18.4969.

SOUZA, E. S. A formação de modelos mentais na sala de aula. Revista Exitus, Santarém, v. 3, n. 1, p. 169-184, 2017. Disponível em:

<http://ufopa.edu.br/portaldeperiodicos/index.php/revistaexitus/article/view /256>. Acesso em: 12 mai. 2020.

SOARES, C.; VIANA, T. Jovita Alves Feitosa: memórias que contam a história da educação nas prisões cearenses. Educação \& Formação, Fortaleza, v. 1, n. 1, jan/abr, p. 140-158, 2016. Disponível em: <https://revistas.uece.br/index.php/redufor/article/view/96>. Acesso em: 17 abr. de 2020. 
THÜRLER, D.; DOS SANTOS, J. L. Um debate sobre a escola como tecnologia político-cultural. Revista Tempos e Espaços em Educação, São Cristóvão, v. 7, n. 14, p. 29-44, 2014. Disponível em: $<$ https://seer.ufs.br/index.php/revtee/article/view/2950>. Acesso em: 3 jan. 2020. DOI: https://doi.org/10.20952/revtee.v0i0.2950.

TANCREDI, R. M.; REALI, A. M. O que um mentor precisa saber? Ou: Sobre a necessidade de um mentor construir uma visão multifocal. Revista Exitus, Santarém, v. 1, n. 1, p. 33-44, 2017. Disponível em: <http://www.ufopa.edu.br/portaldeperiodicos/index.php/revistaexitus/article /view/203>. Acesso em: 12 mai. 2020.

TANCREDI, R. M. Políticas públicas de formação de professores: o PIBID em foco. Revista Exitus, Santarém, v. 3, n. 1, p. 13-31, 2017. Disponível em: $<$ http://ufopa.edu.br/portaldeperiodicos/index.php/revistaexitus/article/view L246>. Acesso em: 12 mai. 2020.

ULJENS, M. Non-Affirmative curriculum theory in a cosmopolitan era?. Revista Tempos e Espaços em Educação, São Cristóvão, v. 9, n. 18, p. 121-132, 2016. Disponível em: <https://seer.ufs.br/index.php/revtee/article/view/4970>. Acesso em: 21 jan. 2020. DOI: https://doi.org/10.20952/revtee.v9i18.4970.

VIEIRA, C. M.; COELHO, M. A. Sexualidade e deficiência intelectual: concepções, vivências e o papel da educação. Revista Tempos e Espaços em Educação, São Cristóvão, v. 7, n. 14, p. 201-212, 2014. Disponível em: $<$ https://seer.ufs.br/index.php/revtee/article/view/3268>. Acesso em: 3 jan. 2020. DOI: https://doi.org/10.20952/revtee.v0i0.3268.

Recebido em: 27 de fevereiro de 2020 Aprovado em: 13 de maio de 2020 Publicado em: 14 de maio de 2020 